\title{
Interactive comment on "Temporal evolution of chlorine and minor species related to ozone depletion observed with ground-based FTIR at Syowa Station, Antarctica and satellites during austral fall to spring in 2007 and 2011" by $\mathrm{H}$. Nakajima et al.
}

\section{Anonymous Referee \#2}

Received and published: 5 July 2018

The manuscript by Nakajima et al. focuses on ground based FTIR observations of trace species in 18 and $22 \mathrm{~km}$ altitude for the years 2007 and 2011 made from the Japanese Syowa station on Antarctica. These data are compared with co-located MLS data and monthly average ozone sonde data. The manuscript further shows simulations with the chemistry climate model MIROC3.2 nudged to ERA-Interim data for the observation years 2007 and 2011.

Printer-friendly version

Discussion paper 
Although there are likely no severe issues with the data or the simulations, the scientific goal of the manuscript remains completely unclear. I find that it is not sufficient, just to present the observations and simulations without addressing open scientific questions. The authors present no new novel concepts, ideas, or tools. The only thing that is said that they present the first ground based continuous measurements of chlorine species in Antarctica.

Interactive

comment

The model data are displayed in addition to the observations but not on the same altitude levels and they are not used to interpret the observations. There is no obvious connection between the simulations and the observations besides two appendix figures that contain the time series of the chlorine compounds and ozone over Syowa station from model and observations.

With respect to the interpretation of the data, it seems that only few aspects of the observations and the simulations are mentioned. Most of them are in line of what is expected and shown in standard chemistry model runs over the last two decades. The simulations seem to be in line with the observations. But it remains completely unclear, what the message of the paper is.

Furthermore, there are many small inaccuracies in the text, some of them are summarised below. Also, many informations are not given precisely, such that the reviewer needs to guess, what the authors meant. Because of the missing scientific concept, I would not recommend the paper for publication in Atmos. Chem. Phys.

\section{General}

The introductions lists some textbook knowledge but it is not clear, why it is at all important in the context of the manuscript.

The use of $\mathrm{ClO}$ data as done in this paper is problematic, since one needs to take into 
account the diurnal cycle typically involving $\mathrm{Cl}_{2} \mathrm{O}_{2}$ as a nighttime reservoir. Observations (fig 6-12) are likely for different local times and are therefore not comparable. As in the 3-hourly model data of fig 17 , no diurnal cycle is visible, it is likely a zonal average over daytime and nighttime data. That is not useful for comparison. Potentially this is the cause of the $\mathrm{ClO}$ difference in figs $\mathrm{B} 1$ and $\mathrm{B} 2$.

Figures 13-16 show the model output on the $50 \mathrm{hPa}$ level for 4 different times. It is not so clear, what can be learned from these figures. Also it would be better to not use a different vertical coordinate (pressure) for the model results as opposed to the observations (altitude).

fig 10/11 shows $\mathrm{Cl}_{y}$ (MLS) relative to $\mathrm{Cl}_{y}{ }^{*}\left(\mathrm{MLS} \mathrm{N} \mathrm{N}_{2} \mathrm{O}\right.$ ), even though that should be described more clearly. In the context $\mathrm{Cl}_{y}$ (without star) is defined as $\mathrm{ClO}+\mathrm{ClONO}_{2}+$ $\mathrm{HCl}$. However, there are no $\mathrm{ClONO}_{2}$ observations of MLS. This needs to be clarifies.

\section{Details}

page 1/line 16 "is not well understood": I don't think that this statement is justified.

1/22 PSC saturation temperature: you likely mean "PSC existence temperature".

2/3: "from active chlorine" or "from ClO" ?

2/17: the expression "inert chlorines" for $\mathrm{HCl}$ and $\mathrm{ClONO}_{2}$ is not typical, please use the wording "chlorine reservoirs" (as in 3/31).

3/4-14: The chlorine deactivation into $\mathrm{ClONO}_{2}$ or $\mathrm{HCl}$ is mentioned, but not that it depends on ozone (Douglass et al. 1997, Grooß et al., 2005 JAS, Grooß et al., 2011 etc;).

3/19: the phrase "super-recovery" is not ideal. It is sometimes used for ozone but not often for $\mathrm{ClONO}_{2}$. 
3/22: ozone has been monitored before the discovery of the ozone hole. (otherwise the ozone hole would not have been discovered).

4/18: "analysis" Do you mean retrieval of tracer profiles from the FTIR spectra?

4/22: how many layers exactly?

5/12: As you only show 14 coincident measurements within a period of 3 months, I would not call this chapter "Validation".

5/31: You show results from MLS Version 3.3 data. Why do you not use version 4.x?

6/8: How exactly do you identify the coincident CALIPSO PSCs? Orbit within a certain distance from Syowa station? PSCs of what type at what altitude?

6/12-15: This seems to be a speculation. It is not clear how this statement is proven in this context.

6/16: You use the term "temporal variations" several times, where I think it is (only) a time series.

6/16: define the expression $\mathrm{Cl}_{y}{ }^{*}$.

6/17: add "for all ground-based and satellite based observations used in this study" (or similar).

$8 / 5$ ratios of each species with respect to $\mathrm{Cl}_{y}{ }^{*}$.

9/1ff: It has not been said over what time the data were collected, how the anticorrelation was evaluated (MIPAS and MLS have different orbits).

page 9/line 1-6 (anti-correlation of MIPAS $\mathrm{CIONO}_{2}$ and MLS CIO, fig 12): If is said that this is due to the PV (eq. latitude) dependence. Could it also be that this occurs because of the time dependence of the deactivation throughout the days 220-260? The slope of the regression line is not given in the text nor a statement of what would be expected from the model. What does this slope or correlation mean scientifically? 
This correlation in the phase of chlorine deactivation is definitely no surprise.

9/24 "About 50This statement is inaccurate (do you mean at the $50 \mathrm{hPa}$ level equally ACPD from the vortex edge to the core? Or also at the other levels? It is at least rather hard to read a number of percentage ozone loss from this figure.

9/33f "Inside the polar vortex, depletion of $\mathrm{O}_{3}, \mathrm{NO}_{2}, \mathrm{HNO}_{3}$, and $\mathrm{ClONO}_{2}$ continued" Most of the species are already near zero. It is not clear from the figure how you see continuing depletion. Also I would not expect further ozone depletion, if active chlorine returned more or less to zero.

10/23-28: The continuous loss of $\mathrm{HCl}$ seems to look differently than in the study by Grooß et al. that you mention. The conclusions of that study are not given properly. It is not clear, whether you include an additional process like ionisation by cosmic rays or cross vortex edge $\mathrm{ClONO}_{2}$ flow due to Solomon et al. in your model. Or does the $\mathrm{HCl}$ just deplete because of the large diffusivity that is present due to the low model resolution $(2.8 \times 2.8$ degrees $)$ ?

11/18f: I do not see this good agreement between model and FTIR in the figures.

figure 5: How was $\mathrm{T}_{N A T}$ and $\mathrm{T}_{i c e}$ derived? What data for $\mathrm{HNO}_{3}$ and $\mathrm{H}_{2} \mathrm{O}$ were used?

figure 12: There must be something wrong with the colour coding of the PV in the panels. I would expect about a factor 2 difference in PV between 18 and $22 \mathrm{~km}$ and also PV values significantly below -85 PVU at $22 \mathrm{~km}$.

figure 17: "Three-hourly zonal-mean temporal variations" What do you mean by variations? It only looks like zonal mean values.

figures B1/B2: Here the model is labelled CTM. Is it really? In the paper you always talk about a CCM. 


\section{Typos/grammar}

ACPD

6/12: other reason -> "other reasons" or "an other reason"

$8 / 32$ shows

Interactive comment on Atmos. Chem. Phys. Discuss., https://doi.org/10.5194/acp-2018-505,

Interactive

comment 2018. 